\title{
The use of inhaled antibiotic therapy in the treatment of ventilator-associated pneumonia and tracheobronchitis: a systematic review
}

\author{
Christopher J. Russell ${ }^{1,2^{*}}$ D, Mark S. Shiroishi ${ }^{3}$, Elizabeth Siantz ${ }^{6}$, Brian W. Wu ${ }^{4}$ and Cecilia M. Patino ${ }^{5}$
}

\begin{abstract}
Background: Ventilator-associated respiratory infections (tracheobronchitis, pneumonia) contribute significant morbidity and mortality to adults receiving care in intensive care units (ICU). Administration of broad-spectrum intravenous antibiotics, the current standard of care, may have systemic adverse effects. The efficacy of aerosolized antibiotics for treatment of ventilator-associated respiratory infections remains unclear. Our objective was to conduct a systematic review of the efficacy of aerosolized antibiotics in the treatment of ventilator-associated pneumonia (VAP) and tracheobronchitis (VAT), using the Cochrane Collaboration guidelines.
\end{abstract}

Methods: We conducted a search of three databases (PubMed, Web of Knowledge and the Cochrane Collaboration) for randomized, controlled trials studying the use of nebulized antibiotics in VAP and VAT that measured clinical cure (e.g., change in Clinical Pulmonary Infection Score) as an outcome measurement. We augmented the electronic searches with hand searches of the references for any narrative review articles as well as any article included in the systematic review. Included studies were examined for risk of bias using the Cochrane Handbook's "Risk of Bias" assessment tool.

Results: Six studies met full inclusion criteria. For the systemic review's primary outcome (clinical cure), two studies found clinically and statistically significant improvements in measures of VAP cure while four found no statistically significant difference in measurements of cure. No studies found inferiority of aerosolized antibiotics. The included studies had various degrees of biases, particularly in the performance and detection bias domains. Given that outcome measures of clinical cure were not uniform, we were unable to conduct a meta-analysis.

Conclusions: There is insufficient evidence for the use of inhaled antibiotic therapy as primary or adjuvant treatment of VAP or VAT. Additional, better-powered randomized-controlled trials are needed to assess the efficacy of inhaled antibiotic therapy for VAP and VAT.

Keywords: Antibiotics, Inhaled, Antibiotics, Aerosolized, Ventilator-associated pneumonia, Therapy

\footnotetext{
* Correspondence: crussell@chla.usc.edu

'Division of Hospital Medicine, Children's Hospital Los Angeles, 4650 Sunset

Blvd, Mailstop \#94, Los Angeles, California 90027, USA

${ }^{2}$ Department of Pediatrics, Keck School of Medicine, University of Southern

California, Los Angeles, California, USA

Full list of author information is available at the end of the article
} 


\section{Background}

Ventilator-associated pneumonia (VAP) is a healthcareassociated infection (HAI) that affects 10-28 \% of patients receiving mechanical ventilation in the intensive care unit (ICU) [1, 2]. Between 24 and $76 \%$ of patients with VAP die [1], with the mortality attributable to VAP estimated at approximately $10 \%$ [2]. VAP prevention strategies include keeping the patient's head of the bed raised at $30-45^{\circ}$, use of chlorohexadine oral care, and minimizing mechanical ventilation days through daily readiness-to-wean trials [2]. Treatment of VAP includes administering broad-spectrum intravenous antibiotics targeted at different bacterial classes (e.g., gram-negative bacteria, anaerobes). Adult infectious disease guidelines published in 2005 recommend that efforts should be made to shorten antibiotic courses for VAPs to limit adverse effects [3]. Antibiotics used to treat these infections may cause systemic morbidity, including acute kidney injury and C. difficile infections. Use of broadspectrum antibiotic therapy against gram-negative bacterial causes of nosocomial ICU pneumonia have been associated with increased bacterial antibiotic resistance rates and selection for more virulent pathogens [4].

One potential therapeutic intervention for VAP and VAT is aerosolized antibiotics. VAP treatment guidelines published in 2005 do not address the use of inhaled antibiotics in the treatment or prevention of VAP and state that "more data are needed on this type of therapy before determining its value." [3] Since publication of this guideline, several groups have published clinical trials assessing the use of inhaled antibiotics for the prevention and treatment of VAP and VAT. Aerosolized antibiotics may be efficacious in the treatment of respiratory infections by delivering antibiotics directly to the infection source (e.g., lungs), increasing antibiotic concentration to overcome antimicrobial resistance while limiting systemic absorption and decreasing drug toxicity. Animal models testing aerosolized versus intravenous antibiotic therapy for treatment of Pseudomonas aeruginosa demonstrated decreased bacterial load and increased lung tissue antibiotic concentrations with use of aerosolized antibiotics compared with intravenous antibiotics [5, 6]. However, the role of aerosolized antibiotics in the treatment of VAP and VAT in humans remains unclear. The objective of the current systematic review is to assess, in patients with diagnosed VAP or VAT, the efficacy and safety of using inhaled antibiotics for treatment of VAP or VAT.

\section{Method}

\section{Search strategy}

Our systematic review's study protocol (available upon request) was developed using the guidelines set forth by the Cochrane Collaboration [7] and the Preferred
Reporting Items for Systematic Reviews and MetaAnalyses (PRISMA) [8]. In October 2014, we searched three electronic databases (Pubmed, Cochrane Collaboration, and Web of Knowledge) for randomized controlled trials that examine use of inhaled antibiotic therapy in the treatment of VAP and VAT with the technical support of an expert medical science librarian at the University of Southern California (see Additional file 1 for one search example).

\section{Inclusion criteria}

Included studies met all of the following criteria:

1. Patients: Study population was mechanically ventilated patients diagnosed with VAP or VAT

2. Intervention: Use of inhaled antibiotics for treatment of VAP or VAT compared to OR in addition to intravenous antibiotics

3. Reported outcomes of a randomized controlled trial, and

4. Outcome: Reported on some measurement of clinical cure as an outcome (e.g. clinical pulmonary infection score [CPIS])

Studies were excluded if they were written in a language other than English, included patients on chronic positive-pressure ventilation not hospitalized or studied the use of inhaled antibiotics in patients who are not intubated. Multiple published reports from a single study were treated as a single data point.

\section{Data extraction and analysis}

Two authors (MS, BW) independently reviewed and screened all studies for inclusion using a screening tool to increase reproducibility. All study authors reviewed studies when there were disagreements about study inclusion and a consensus was reached. The following information was extracted and documented from studies that met inclusion criteria: study participant characteristics and setting, description of antibiotics studied including route of administration, doses, frequencies, and duration of treatment, the study period, length of follow up and outcomes such as successful treatment.

The methodological quality of all studies that met inclusion criteria was appraised using the Cochrane Collaboration's tool for assessing the risk of bias in the reporting of clinical trials [7]. This tool rates the quality of a study's evidence by examining the potential bias in selection, performance, detection, attrition, and reporting. Two authors (MS, BW) assessed the risk of bias for each study that met inclusion criteria study and any discrepancies were reconciled by consensus among the authors. 


\section{Results}

Figure 1 details the study selection process. Our search yielded 272 unduplicated articles, of which 40 were excluded because they were not written in English and did not meet inclusion criteria in review of the English translation. Our review includes six studies describing results of randomized controlled trials on the use of inhaled antibiotics for the treatment of VAP or VAT [9-14]. Three hundred and five patients were enrolled across all studies. One study each tested aerosolized tobramycin [9], amikacin [11], colisthmethate sodium (CMS) [14], and combined amikacin/ceftazidime [10], respectively; two studies based aerosolized antibiotic choice upon culture results at the treating physician's discretion [12, 13]. Five studies $[9,10,12-14]$ utilized clinical measures of VAP treatment success as a primary outcome measure, while one study [11] included measures of treatment success as a secondary outcome. Definition of the main outcome

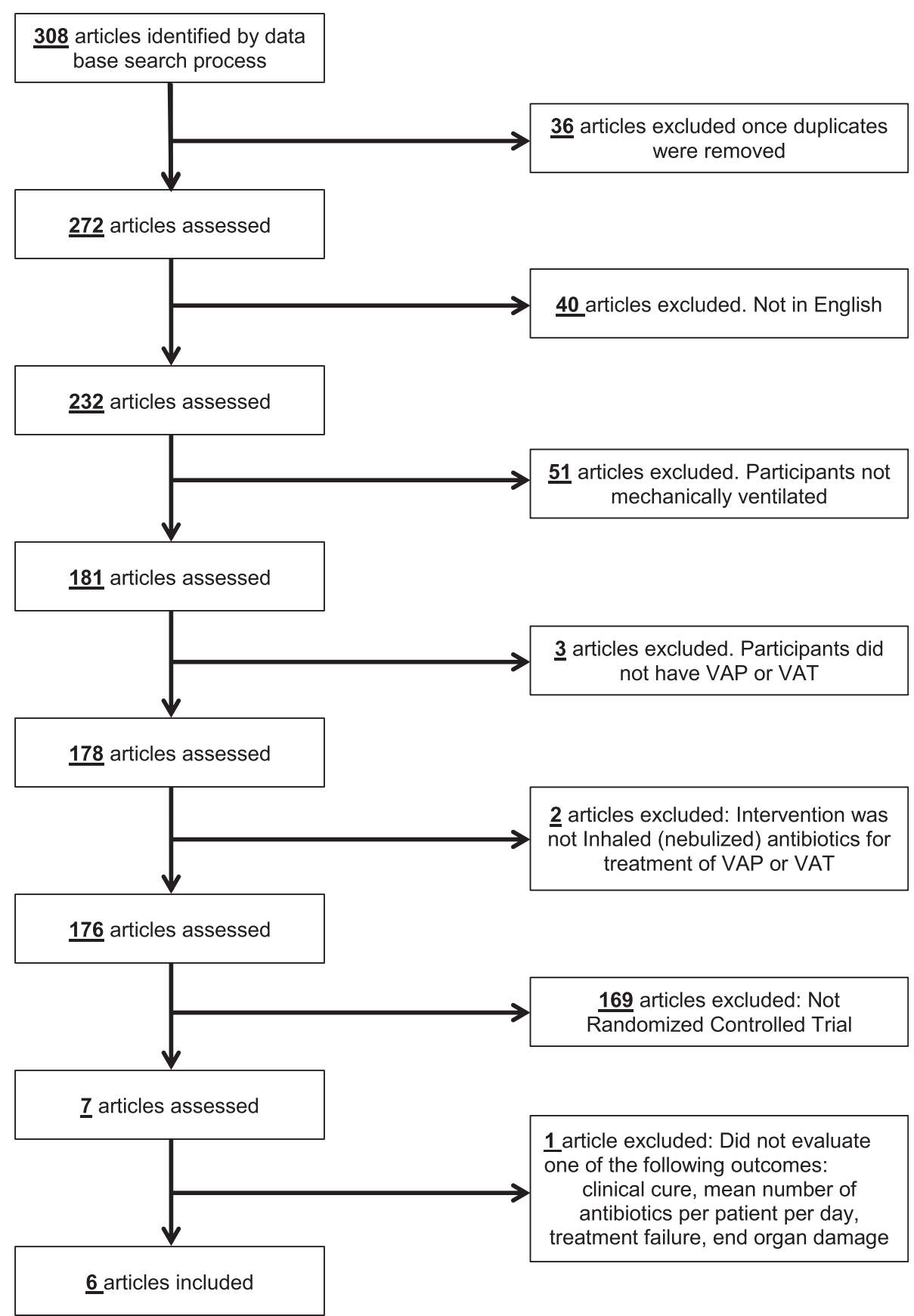

Fig. 1 PRISMA diagram 
variable, successful treatment, varied widely across studies. Two studies included rigorous and objective measures of cure (e.g., Clinical Pulmonary Infection Score; range 0-12), while others relied on less objective definitions (e.g., Favorable clinical outcome, as defined by the treating physician or study team; Table 1). Third, the study quality and risk for bias varied across the studies (Table 2). Length of the study period varied from 7 to 36 months.

Overall, two studies $[12,13]$ found statistically significant improvements in the primary clinical outcome (clinical cure). Palmer and colleagues [12] reported that aerosolized antibiotics resulted in significantly reduced signs of respiratory infection and clinical pulmonary infection score when compared to placebo score (mean change $\pm \mathrm{SD}=-1.42 \pm 2.3 ; p=0.02$ ). With respect to their secondary outcomes, this study reported that aerosolized antibiotics resulted in lower white blood cell count at day 14 (in $10^{3} / \mathrm{mm}^{3}$ : AA: $9.2 \pm 3.3$ vs placebo: $14.9 \pm 8.1$; $p=0.02$ ), reduced bacterial resistance (AA: $0 \%$ vs placebo: $33 \% ; p<0.01$ ), reduced use of systemic antibiotics (AA: $47 \%$ vs placebo: $70.8 \% ; p<0.05$ ) and increased ventilator weaning (AA: $80 \%$ vs placebo: $45 \% ; p<0.05)$. A second study by Palmer [13] found that compared with placebo, aerosolized antibiotics significantly reduced clinical pulmonary infection score (AA: $9.3 \pm 2.7$ to $5.3 \pm 2.6$ vs placebo: $8.0 \pm 2.1$ to $8.6 \pm 2.6 ; p<0.001)$.

Three studies $[9,11,14]$ found no difference in clinical cure rates when comparing intravenous antibiotics to intravenous antibiotics combined with aerosolized antibiotics. In an adequately-powered study, Rattanaumpawan and colleagues found no difference in favorable clinical response between aerosolized colisthmethate and aerosolized saline placebo, when used with intravenous antibiotics at the discretion of the treating physician [14]. A small pilot study $(n=10)$ by Hallal et al. [9] found that $100 \%$ of VAP patients treated with aerosolized tobramycin and intravenous $\beta$-lactam antibiotics had clinical resolution of VAP, compared to $60 \%$ of those receiving combined intravenous tobramycin and $\beta$-lactam antibiotics; however, this result was not statistically significant difference due to low power. Niederman et al. [11] randomized subjects to an investigational form of amikacin (BAY41-6551) every $12 \mathrm{~h}$, every $24 \mathrm{~h}$ or placebo every $12 \mathrm{~h}$. The primary outcome in the study was the combination of tracheal aspirate amikacin maximum concentration $\geq 6400 \mu \mathrm{g} / \mathrm{mL}$ and ratio of area under aspirate concentration-time curve to minimum inhibitory concentration-time curve $(0-24 \mathrm{~h})$ to minimum inhibitory concentration $\geq 100$ on day 1 . Fifty percent and $16.7 \%$ of their patients achieved the primary endpoint in the every $12 \mathrm{~h}$ and every $24 \mathrm{~h}$ groups, respectively. Secondary outcomes such as clinical cure rates were not significantly different between the every $12 \mathrm{~h}$, every $24 \mathrm{~h}$ and placebo groups, respectively $(p=0.467)$. However, a statistically significant difference in mean antibiotics per patient per day was seen between the three groups, 0.9 in the every $12 \mathrm{~h}, 1.3$ in the every $24 \mathrm{~h}$ and 1.9 in the placebo groups, respectively ( $p=0.02$ between the groups). In the single study that compared aerosolized antibiotics alone to intravenous antibiotics, $\mathrm{Lu}$ et al [10] found a $21.4 \%$ difference between nebulized and intravenous amikacin/ ceftazidime with respect to successful treatment (70 vs $55 \% ; p=0.33)$, a $50 \%$ reduction in treatment failure ( 15 vs $30 \% ; p=0.26$ ), and no difference superinfection with other microorganisms (15 vs $15 \%$; $p=1.00$ ) [10]. Overall, no studies demonstrated that AA were associated with poorer patient outcomes.

\section{Risk of bias assessment (Table 2)}

The risk of bias varied across the six studies evaluated in this systematic review. All studies had low or unclear risk of selection bias. Three studies [10, 11, 14] had high risk of performance bias due to lack of blinding. Two studies $[10,11]$ had high risk of detection bias due to lack of blinding for those making the clinical cure assessments, while one study [14] had unclear risk of detection bias because they did not state who made the assessments of clinical cure. Two studies [11, 12] had high risk of attrition due to inability to conduct intentionto-treat analysis [11] or high termination rate [12]. One study [12] had high risk of reporting bias, as they did not report clinical outcomes for all patients. Finally, two studies $[11,12]$ had high risk of conflict of interest bias given that they were industry sponsored, while two additional studies $[9,13]$ did not discuss funding sources or other conflicts of interest. Overall, only two studies (Hallal [9], Palmer [13]) were assessed with low or unclear risk of bias across all domains, while Niederman [11] had a high risk of bias assessed across five of six domains.

\section{Discussion}

Our systematic review found six articles that report that aerosolized antibiotics may improve clinical cure for VAP, particularly when combined with intravenous antibiotics. The strengths of the current systematic review include use of the Cochran Collaboration/PRISMA [7, 8] guidelines for reporting of systematic reviews and the inclusion of only randomized controlled trials. All included studies had a study arm that used either placebo aerosolized medications or only systemic antibiotics for comparison. Included studies used aerosolized antibiotics with a similar spectrum of antibacterial coverage. Finally, the majority of the studies included had high external validity in allowing treating clinicians' discretion to determine use of systemic antibiotics and other intensive care measures. 
Table 1 Study Characteristics, Quality and Results, in Chronological Order

\begin{tabular}{|c|c|c|c|c|c|c|}
\hline Author and year & $\begin{array}{l}\text { Study Participants } \\
\text { (age, in years) }\end{array}$ & $\begin{array}{l}\text { Description of } \\
\text { intervention }\end{array}$ & Study period & $\begin{array}{l}\text { Length of } \\
\text { follow up }\end{array}$ & $\begin{array}{l}\text { Primary Outcome } \\
\text { (successful treatment) }\end{array}$ & Results \\
\hline Hallal, et al, 2007 [9] & $\begin{array}{l}N=10 \\
\text { Age: } 23-72 \text { (Mean age: } \\
\text { AA 52.6, IV 53.6) }\end{array}$ & $\begin{array}{l}\text { Inhaled tobramycin or IV } \\
\text { tobramycin AND IV } \beta \text {-lactam }\end{array}$ & 7 months & 28 days & Resolution of VAP & $\begin{array}{l}100 \% \text { of AA vs. } 60 \% \text { of IV } \\
\text { patients had clinical resolution } \\
\text { of VAP. No p value reported. }\end{array}$ \\
\hline Palmer et al, 2008 [12] & $\begin{array}{l}N=43 \\
\text { Age: 19-92 (Mean age: } \\
\text { AA 62.3, placebo 62.7) }\end{array}$ & $\begin{array}{l}\text { AA or saline placebo AND } \\
\text { systemic antibiotics (per } \\
\text { treating MD) was given for } \\
14 \text { days or until extubation }\end{array}$ & 12 months & 28 days & $\begin{array}{l}\text { Centers for Disease Control } \\
\text { National Nosocomial Infection } \\
\text { Survey diagnosis of ventilator- } \\
\text { associated pneumonia (VAP) } \\
\text { and clinical pulmonary } \\
\text { infection Score (CPIS) }\end{array}$ & $\begin{array}{l}\text { AA group had reduced signs } \\
\text { of respiratory infection [Centers } \\
\text { for Disease Control National } \\
\text { Nosocomial Infection Survey } \\
\text { and VAP ( } 73.6 \% \text { to } 35.7 \% \\
\text { vs. placebo: } 75 \% \text { to } 78.6 \%) \\
\text { and reduction in clinical } \\
\text { pulmonary infection score } \\
\text { (-1.42 vs. placebo: + 0.04), } \\
\text { (both p } \leq .05) \text {. }\end{array}$ \\
\hline Rattanaumpawan et al, 2010 [14] & $\begin{array}{l}N=100 \text { (Mean age: } \\
\text { AA 70.2, placebo 66.2) }\end{array}$ & $\begin{array}{l}\text { Nebulized colistimethate } \\
\text { sodium or nebulized sterile } \\
\text { normal saline AND systemic } \\
\text { antibiotics per treating MD }\end{array}$ & 38 months & 28 days & Favorable clinical outcome & $\begin{array}{l}\text { Favorable clinical outcome was } \\
51.0 \% \text { in the AA group and } 53.1 \% \\
\text { in the placebo group ( } p=0.84 \text { ). } \\
\text { Significant increase in favorable } \\
\text { microbiological outcome in AA vs. } \\
\text { placebo group ( } 60.9 \text { vs. } 38.2 \% \text {; } \\
p=0.03 \text { ) }\end{array}$ \\
\hline Lu et al, 2011 [10] & $\begin{array}{l}N=40 \text { patients Ages } \\
43-77 \text { (Mean age: } \\
\text { AA 58, IV 60) }\end{array}$ & $\begin{array}{l}\text { Nebulized ceftazidime and } \\
\text { amikacin OR IV ceftazidime } \\
\text { and amikacin/ciprofloxacin. }\end{array}$ & 36 month & 28 days & Successful treatment & $\begin{array}{l}\text { AA and IV groups performed } \\
\text { similar in terms of successful } \\
\text { treatment ( } 70 \text { vs. } 55 \% ; p=0.33 \text { ). }\end{array}$ \\
\hline Niederman et al, 2012 [11] & $\begin{array}{l}N=69 \text { (Mean age: AA } \\
\text { q12h 56.1, AA q24h } \\
62.8, \text { or placebo 62.0) }\end{array}$ & $\begin{array}{l}\text { Inhaled amikacin (BAY41-6551) } \\
\text { q12h, q24h, or placebo q12h } \\
\text { for } 7-14 \text { days, plus standard } \\
\text { IV antibiotics }\end{array}$ & 13 months & 31 days & $\begin{array}{l}\text { Clinical cure (secondary } \\
\text { study outcome) }\end{array}$ & $\begin{array}{l}\text { Clinical cure achieved in } 93.8 \% \\
\text { (AA q12h), } 75 \% \text { (AA q24h) and } \\
87.5 \% \text { (placebo; } p=0.467) \text {. }\end{array}$ \\
\hline Palmer et al, 2014 [13] & $\begin{array}{l}N=43 \text { (Mean age AA } \\
57.5, \text { placebo 60.6) }\end{array}$ & $\begin{array}{l}\text { AA or saline placebo AND } \\
\text { systemic antibiotics (per } \\
\text { treating MD) was given for } \\
14 \text { days or until extubation }\end{array}$ & Does not state & 14 days & $\begin{array}{l}\text { Clinical Pulmonary Infection } \\
\text { Score (CPIS) }\end{array}$ & $\begin{array}{l}\text { CPIS score in AA significantly } \\
\text { reduced when compared to } \\
\text { placebo (Mean } \pm \text { SE AA: } 9.3 \pm 2.7 \\
\text { to } 5.3 \pm 2.6 \text { vs. placebo: } 8.0 \pm 23 \\
\text { to } 8.6 \pm 2.10 ; p=0.0008 \text { ) }\end{array}$ \\
\hline
\end{tabular}

Abbreviations: AA aerosolized antibiotics, CPIS Clinical Pulmonary Infection Score; SEM standard error of the mean, VAP ventilator-associated pneumonia 
Table 2 Bias Assessment for Individual Studies

\begin{tabular}{lllllll}
\hline Study & Selection Bias & Performance Bias & Detection Bias & Attrition Bias & Reporting Bias & Conflict of Interest \\
\hline Hallal, et al. (2007) [9] & Low & Low & Low & Low & Low & Unclear \\
Palmer et al. (2008) [12] & Low & Low & Low & High & Low & High \\
Rattanaumpawan et al. (2010) [14] & Unclear & High & Unclear & Low & Low & Low \\
Lu et al. (2011) [10] & Unclear & High & High & Low & Low & Low \\
Niederman et al. (2012) [11] & Low & High & High & High & High & High \\
Palmer et al. (2014) [13] & Low & Low & Low & Low & Low & Unclear \\
\hline
\end{tabular}

Of the studies included, two reported statistically significant clinical improvement when both nebulized and intravenous antibiotics were delivered, compared to intravenous antibiotics alone [12, 13]. Four studies showed no statistical differences in clinical cure between patients who received IV or aerosolized antibiotics [10] or when nebulized antibiotics were added to intravenous antibiotics $[9,11,14]$. Overall, only three studies [12-14] had adequate power to detect a difference in clinical cure rate; while the three remaining studies were pilot studies $[9,10]$ or were powered for another clinical outcome [11]. Only one study used aerosolized antibiotics without systemic antibiotics; this study showed a clinically meaningful but non-statistically significant $21.4 \%$ relative increase in successful treatment using aerosolized antibiotics [10].

One potential explanation for the disparate results involves the antibiotic nebulization technique. Achieving adequate treatment of any pulmonary infection via inhaled antibiotics requires delivery of sufficient antibiotics to the lungs. This involves adequate nebulization of the antibiotics into appropriate particle size for delivery in high concentrations. Previous research demonstrates that certain types of nebulizers (e.g. jet nebulizers) may be less efficient at antibiotic delivery than other methods (e.g ultrasonic or vibrating plate nebulizers) for patients on mechanical ventilation [15]. Only three of the studies [11-13] included used nebulizers with data that demonstrated that they had adequate antibiotic delivery to the airway or lung. Of the three papers using untested nebulizers, one used a non-specified vibrating plate nebulizer [10], another a Pari-Jet nebulizer [9] and the last did not specify the nebulizer type [14]. Of all six studies, the two studies that found positive results had appropriate nebulizers [12, 13]. Thus, differences seen in efficacy of inhaled antibiotics may be due to differential delivery of antibiotics to the target tissue.

This systematic review has several limitations. First, we excluded studies that were not randomized, controlled trials written in English. By excluding observational studies, such as cohort and case-control studies, we decreased the number of studies examined. This may have affected the external validity of this systematic review by missing studies showing significant changes that might affect the overall estimate of effect sizes. Second, the primary study outcome of the systematic review, clinical cure, was not defined uniformly in each of the included studies. Thus, there may be differential misclassification of the study outcome leading to information bias that might cause over- or underestimation of the effect size. While all were randomized, controlled trials, two $[10,14]$ were not blinded fully and relied on nonblinded evaluation of clinical cure and two [11, 12] were sponsored in part by pharmaceutical companies. Unblinded studies may introduce bias by allowing the outcome evaluators to misclassify study outcomes due to treatment groups. Fourth, in five of the six studies, all study participants were given intravenous antibiotics at the direction of the treating physician. Therefore, we cannot determine the efficacy of using solely aerosolized antibiotics, when compared to systemic antibiotics in the treatment of VAP or VAT. Lastly, publication bias may affect the current study's conclusions, as we may have missed studies that met inclusion criteria but that were not published or studies presented in abstract form that were submitted to conferences but never published. However, that four out of six studies had null findings suggests that there was less publication bias specifically due to the absence of statistically significant results.

\section{Conclusion}

This systematic review found insufficient evidence for the use of inhaled antibiotic therapy as primary or adjuvant treatment of VAP or VAT. Given the variations in study protocols, antibiotics studied and vague definition of clinical cure as an outcome measure, additional, adequately powered randomized-controlled trials with strict definitions of outcome assessments and use of previously validated nebulizer delivery methods for antibiotic administration are needed to assess the efficacy of inhaled antibiotic therapy for VAP and VAT. 


\section{Additional file}

Additional file 1: PubMed Electronic search method. (PDF $10 \mathrm{~kb}$ )

\section{Abbreviations}

AA: aerosolized antibiotics; HAl: healthcare-associated infection; ICU: intensive care unit; LOS: length of stay; VAP: ventilator-associated pneumonia; VAT: ventilator-associated tracheobronchitis.

\section{Competing interests}

The authors declare that they have no competing interests.

\section{Authors' contributions}

CR, MS, ES and BW conceptualized and designed the study protocol. MS and BW reviewed and screened all studies for inclusion and assessed included studies for bias. CR and ES drafted the initial manuscript. MS, BW and CS reviewed and critically revised the manuscript. All authors approved the final manuscript as submitted.

\section{Acknowledgements}

Robert Johnson, MLIS for assistance with literature searches. Jon M. Samet and Melissa Wilson for guidance. Drs. Russell and Shiroishi are KL2 Scholars and Drs. Siantz and Wu are TL1 Trainees awarded through Southern California Clinical and Translational Science Institute at University of Southern California, Keck School of Medicine. The project described was supported by the National Center for Advancing Translational Sciences, National Institutes of Health (NIH), through Grant Award Numbers KL2TR000131 and TL1TR000132. The content is solely the responsibility of the author(s) and does not necessarily represent the official view of the $\mathrm{NIH}$.

\section{Author details}

'Division of Hospital Medicine, Children's Hospital Los Angeles, 4650 Sunset Blvd, Mailstop \#94, Los Angeles, California 90027, USA. ²Department of Pediatrics, Keck School of Medicine, University of Southern California, Los Angeles, California, USA. ${ }^{3}$ Department of Radiology, Keck School of Medicine, University of Southern California, Los Angeles, California, USA. ${ }^{4}$ MD-PhD Program, Keck School of Medicine, University of Southern California, Los Angeles, Calfornia, USA. ${ }^{5}$ Department of Preventive Medicine, Keck School of Medicine, University of Southern California, Los Angeles, California, USA. ${ }^{6}$ School of Social Work, University of Southern California, Los Angeles, California, USA.

Received: 5 December 2015 Accepted: 25 February 2016 Published online: 08 March 2016

\section{References}

1. Chastre J, Fagon JY. Ventilator-associated pneumonia. Am J Respir Crit Care Med. 2002;165:867-903.

2. Susan E, Coffin MM, Michael Klompas MD, David Classen MM, Kathleen M, Arias MC, et al. Strategies to prevent ventilator-associated pneumonia in acute care hospitals. Infect Control Hosp Epidemiol. 2008;29:S31-40.

3. Guidelines for the management of adults with hospital-acquired, ventilator-associated, and healthcare-associated pneumonia. Am J Respir Crit Care Med. 2005, 171:388-416.

4. Gaynes R, Edwards JR. Overview of nosocomial infections caused by gram-negative bacilli. Clin Infect Dis. 2005;41:848-54.

5. Ferrari F, Lu O, Girardi C, Petitjean $\mathrm{O}$, Marquette $\mathrm{CH}$, Wallet F, et al. Nebulized ceftazidime in experimental pneumonia caused by partially resistant Pseudomonas aeruginosa. Intensive Care Med. 2009;35:1792-800.

6. Lu Q, Girardi C, Zhang M, Bouhemad B, Louchahi K, Petitjean O, et al. Nebulized and intravenous colistin in experimental pneumonia caused by Pseudomonas aeruginosa. Intensive Care Med. 2010;36:1147-55.

7. Higgins JPT, Green S (editors). Cochrane Handbook for Systematic Reviews of Interventions Version 5.1.0 [updated March 2011]. The Cochrane Collaboration, 2011. Available from www.cochrane-handbook.org.

8. Liberati A, Altman DG, Tetzlaff J, Mulrow C, Gotzsche PC, loannidis JP, et al, The PRISMA statement for reporting systematic reviews and meta-analyses of studies that evaluate healthcare interventions: explanation and elaboration. BMJ. 2009;339:b2700.
9. Hallal A, Cohn SM, Namias N, Habib F, Baracco G, Manning RJ, et al. Aerosolized tobramycin in the treatment of ventilator-associated pneumonia: a pilot study. Surg Infect (Larchmt). 2007;8:73-82.

10. Lu Q, Yang J, Liu Z, Gutierrez C, Aymard G, Rouby JJ. Nebulized ceftazidime and amikacin in ventilator-associated pneumonia caused by Pseudomonas aeruginosa. Am J Respir Crit Care Med. 2011;184:106-15.

11. Niederman MS, Chastre J, Corkery K, Fink JB, Luyt CE, Garcia MS. BAY41-6551 achieves bactericidal tracheal aspirate amikacin concentrations in mechanically ventilated patients with Gram-negative pneumonia. Intensive Care Med. 2012;38:263-71.

12. Palmer LB, Smaldone GC, Chen JJ, Baram D, Duan T, Monteforte M, et al. Aerosolized antibiotics and ventilator-associated tracheobronchitis in the intensive care unit. Crit Care Med. 2008;36:2008-13.

13. Palmer LB, Smaldone GC. Reduction of bacterial resistance with inhaled antibiotics in the intensive care unit. Am J Respir Crit Care Med. 2014;189:1225-33.

14. Rattanaumpawan P, Lorsutthitham J, Ungprasert P, Angkasekwinai N, Thamlikitkul V. Randomized controlled trial of nebulized colistimethate sodium as adjunctive therapy of ventilator-associated pneumonia caused by Gram-negative bacteria. J Antimicrob Chemother. 2010;65:2645-9.

15. Rouby JJ, Bouhemad B, Monsel A, Brisson H, Arbelot C, Lu Q. Aerosolized antibiotics for ventilator-associated pneumonia: lessons from experimental studies. Anesthesiology. 2012;117:1364-80.

\section{Submit your next manuscript to BioMed Central and we will help you at every step:}

- We accept pre-submission inquiries

- Our selector tool helps you to find the most relevant journal

- We provide round the clock customer support

- Convenient online submission

- Thorough peer review

- Inclusion in PubMed and all major indexing services

- Maximum visibility for your research

Submit your manuscript at www.biomedcentral.com/submit 